\title{
Avaluació i aprenentatge en espais innovadors AICLE
}

\author{
Elisabeth Eixarch Domènech \\ Universitat Autònoma de Barcelona, Barcelona, Espanya
}

(Article rebut el 18 de novembre de 2010; versió final rebuda el 11 d'abril de 2011)

L'estudi de cas que es presenta en aquest article parteix de la necessitat d'avaluar rigorosament els programes d'innovació d'Aprenentatge Integrat de Contingut i Llengua Estrangera (AICLE) que es porten a terme en alguns centres educatius de secundària de Catalunya. L'estudi avalua les programacions de tres unitats didàctiques AICLE de ciències en anglès a diferents nivells educatius de l'etapa de secundària obligatòria (ESO), d'un Institut de secundària de la Barcelona metropolitana, i presenta una anàlisi detallada de les activitats d'ensenyament-aprenentatge i d'avaluació específicament dissenyades per a les aules AICLE del centre, amb l'objectiu d'establir l'existència o no d'una concordança entre unes i altres, i alhora analitzar l'adequació d'aquestes activitats per avaluar i promoure l'assoliment de dues de les vuit competències que es defineixen com a bàsiques en el Currículum de l'ensenyament secundari obligatori: la competència comunicativa lingüística i audiovisual (Cb1) i la competència d'aprendre a aprendre (Cb5).

\section{Introducció}

La dinàmica d'una societat pluricultural i en constant canvi com la nostra i el valor de la diversitat lingüística i cultural en el marc europeu, són aspectes que fan necessària l’adequació de les dinàmiques educatives a les aules en els centres educatius.

Una de les propostes actuals de renovació didàctica a les aules, és la implementació de programes d'innovació d'Aprenentatge Integrat de Contingut i Llengua, o AICLE. L’acrònim AICLE, segons Navés i Muñoz (1999), fa referència a situacions educatives on una llengua diferent a la llengua primera o L1 és el mitjà amb el qual el contingut és après, aportant una comunicació real, on l’ús natural de la llengua segona o estrangera és possible (Dalton-Puffer 2007).

A l'Institut Cerdanya del Vallès Occidental es porta a terme des del curs 20062007 un programa pilot AICLE, en el qual hi participa professorat de ciències, matemàtiques, orientació i anglès. La coordinació i l'enfocament col·laboratiu entre aquest professorat i la universitat ha estat una peça clau per a aconseguir el plantejament d'un treball integrador i innovador a les aules, així com per abordar les complexes interaccions que es donen a diferents nivells en les aules AICLE. 
El propòsit de l'estudi $^{1}$ que recull aquest article, és el d'analitzar aquest programa pilot d'innovació AICLE des de la doble perspectiva de l'alineació de les activitats d'avaluació amb les d'aprenentatge en les aules AICLE, i l'adequació d'aquestes activitats per avaluar i promoure l'assoliment de dues de les vuit competències que el currículum català defineix com a bàsiques per a l'ensenyament obligatori dins de l'aula, la comunicativa lingüística i audiovisual i la d'aprendre a aprendre.

\section{Marc Teòric}

Aquest treball s’inscriu en la tradició pedagògica de promoció del plurilingüisme de l'equip de treball CLIL-SI ${ }^{2}$ (Content and Language Integrated LearningSemiimmersió), el qual forma part del Grup de Recerca en Ensenyament i Interacció Plurilingües (GREIP) ${ }^{3}$ de la Universitat Autònoma de Barcelona..

El marc teòric que dóna cobertura i suport a l'enfocament, anàlisi i desenvolupament de la recerca comprèn tres blocs, cada un dels quals està relacionat amb els altres configurant els tres aspectes que s'han analitzat al llarg de l'estudi: els programes d'AICLE, l'avaluació i les competències bàsiques.

AICLE: La definició d'AICLE que ha adoptat el projecte del centre i que restringeix la proposada per Dalton-Puffer (2007) presentada a la secció anterior, és la següent:

L'aprenentatge AICLE engloba aquelles realitats educatives que consisteixen en l'ensenyament i aprenentatge de matèries curriculars o continguts acadèmics -diferents dels purament lingüístics- mitjançant una llengua vehicular, en la qual els aprenents tenen una competència comunicativa en desenvolupament ja sigui incipient o avançada, i que promouen de forma explícita:

-El manteniment i desenvolupament de la llengua o llengües primeres de l'aprenent, i la consideració i posada en valor de les formes culturals que les L1 aporten a la comunitat.

-Un enfocament autènticament integrat. És a dir que demostren un doble focus d'atenció pedagògica: la llengua i el contingut, i procuren als alumnes tota l'ajuda necessària per a comprendre, produir i negociar missatges de contingut acadèmic en la llengua meta adoptada com vehicle de comunicació escolar o universitària. (Dalton-Puffer 2007, citat en Escobar 2011: 203-204)

Diversos estudis realitzats per membres de l'equip CLIL-SI (Corredera 2008; Escobar 2004; Evnitskaya i Aceros 2008; Horrillo 2010; Jiménez 2010; Nussbaum i Tuson 
2006; Pallarès 2010; Tapias 2010) demostren que les propostes pedagògiques que promouen l'aprenentatge d'una àrea curricular en llengua anglesa (tercera llengua en el cas de Catalunya) amb un enfocament com el descrit en la definició anterior, contribueixen a abordar les dificultats de comunicació que la L3 comporta, amb activitats de reflexió i interacció a l'aula entre l’alumnat i el professorat que afavoreix el desenvolupament d'estratègies i habilitats lingüístiques (competència comunicativa) i, alhora, les tasques col-laboratives i d'autoregulació que es porten a terme a l'aula, afavoreixen que l'alumnat sigui coneixedor del seu propi procés d'aprenentatge (competència d'aprendre a aprendre).

AVALUACIÓ: L’estudi pretén analitzar l'alineació o no de les activitats d'avaluació i les d'aprenentatge partint de la corrent de recerca que centra els seus estudis en la teoria de l'avaluació per l'aprenentatge, contemplant l'avaluació formativa i la sumativa com a eines de coneixement del propi progrés d'aprenentatge i, per tant, d'afavoriment de l'autoregulació de l'aprenent (Ribas 1998, 2009; Escobar 2002, 2004, 2007; Allal 2006; De Ketele 2006; Sanmartí 2007). Una línia de recerca que considera les activitats d'avaluació com a determinants de les tasques educatives que han d'ajudar als estudiants a desenvolupar estratègies, a trobar el seu propi estil, desenvolupament personal i intel·lectual i reflexió, que els permeti un aprenentatge en profunditat i alhora aconseguir el millor de cada un.

Per a aconseguir una avaluació sostenible (Boud 2003) i una avaluació que serveixi a l'estudiant per aprendre, les activitats que es proposen han de transferir part de la responsabilitat de prendre decisions del professorat a l'aprenent, oferint-li els fonaments per un aprenentatge continuat al llarg de la seva vida i alhora millorar l'aprenentatge del moment.

L’avaluació entesa com a eina d’autoregulació, constitueix forçosament el motor de tot el procés de construcció de coneixement, utilitzant uns instruments autoreguladors monitoritzats pel docent com a mediador, orientant a l'alumnat i donantli evidències del seu propi progrés (Sanmartí 2007). Si es vol potenciar la funció reguladora entre l'alumnat, hem de buscar “que l'alumne s'apropiï dels criteris d'avaluació, dels instruments d’aprenentatge i de la gestió dels propis errors” (Ribas 2009). Una de les eines d'avaluació continua és el Portafoli, una eina potent, adequada a 
la finalitat de crear aprenents de per vida, flexible i integradora, per la qual cosa es suposa adequada als entorns AICLE (Wolf 1991; Escobar 2000; Bazerman 2002).

COMPETÈNCIES BÀSIQUES: El concepte de competència forma part d'un nou discurs pedagògic el qual es basa en la cerca de respostes a les demandes socials del segle XXI. S'ha d'equipar als alumnes amb un conjunt de capacitats que els permeti donar respostes adients a aquestes demandes.

L’any 1997, l’Organització per a la Cooperació i el Desenvolupament Econòmic (OCDE), va encarregar al projecte Definició i Selecció de Competències (DeSeCo) la construcció d'un marc de referència conceptual que comprengués molts àmbits i que fos rellevant per el desenvolupament de les competències clau des de la perspectiva de l'aprenentatge al llarg de tota la vida i que, a més a més, avalués aquestes competències en un marc internacional. Aquesta avaluació és el que es coneix com a Programme for International Student (PISA) el qual té com a objectiu l'avaluació de la capacitat dels joves per a utilitzar els seus coneixements i destreses amb l'objectiu d'afrontar els reptes de la vida real.

A Catalunya els nous currículums LOE (DECRET 143/2007, de 26 de juny) s'alineen amb aquest corrent $\mathrm{i}$ aporten un canvi substancial en aquest sentit: l'aprenentatge per competències. S'estableixen vuit competències bàsiques que tot l'alumnat d'Ensenyament Secundari Obligatori ha d'haver adquirit en finalitzar l'etapa.

Pel que fa a les competències en els quals es centra aquest estudi trobem:

[...] el desenvolupament de la competència lingüística $i$ audiovisual suposa el diferent domini de llengües, tant oralment com per escrit, en múltiples suports i amb el complement dels llenguatges audiovisuals en varietat de contextos i finalitats, com a eina per aprendre a aprendre" i, "aprendre a aprendre implica la consciència, gestió i control de les pròpies capacitats $i$ coneixements des d'un sentiment de competència 0 eficàcia personal, i inclou tant el pensament estratègic, com la capacitat de cooperar, d'autoavaluar-se, i el maneig eficient d'un conjunt de recursos i tècniques de treball intel-lectual, i tot això es desenvolupa per mitja d'experiències d'aprenentatge conscients i gratificants, tant individuals com col-lectives. (DOGC, 2007: 21870).

\section{El context de la investigació}


Les dades que s'analitzen provenen d'un Institut de secundària del Vallès Occidental on s’imparteixen els nivells d’ESO, batxillerat i cicles formatius. Té una plantilla de més de 70 professors/es, i al voltant dels 800 alumnes. El centre està ubicat en un sector que va créixer amb l'onada immigratòria dels anys 60, per això els alumnes són en gran majoria fills o néts d'immigrants. Es tracta d'un barri de classe treballadora. A partir del 2000 i fins ara, hi ha hagut i hi ha un degoteig constant d'estudiants d'origen estranger que arriben al barri. Per tant, actualment, es pot parlar de pluriculturalitat a l'aula. La llengua predominant al barri i de relació entre la majoria dels alumnes és el castellà. El català s’usa principalment en l'àmbit escolar i com a llengua acadèmica.

Des del curs 2006-07 es porta a terme en aquest centre l'experiència d'aprenentatge integrat AICLE en unitats didàctiques (amb diversificació curricular) de ciències i matemàtiques en anglès. El projecte va dirigit a tots els alumnes de l'ESO (de 12 a 16 anys), sense una prèvia selecció.

La investigadora ha estat implicada des d'un començament en el disseny i implementació de les unitats didàctiques AICLE, com a professora de llengua estrangera i tutora dels alumnes del Màster universitari en formació de professorat d'educació secundària obligatòria i batxillerat, formació professional i ensenyaments d'idiomes de la Universitat Autònoma de Barcelona.

De totes les unitats didàctiques AICLE que s'han elaborat, se n'ha seleccionat tres de diferents nivells de l'ESO (1r, 2n i 3r) i de la mateixa àrea curricular de contingut (ciències). Totes les unitats de la mostra han estat planificades i implementades per alumnes del Màster en Formació Inicial de la UAB amb la tutorització i supervisió del professorat titular de l’Institut de les àrees implicades.

Les unitats didàctiques que s’analitzen són:

Taula 1: Informació de les unitats didàctiques analitzades

\begin{tabular}{lll}
\hline \multicolumn{1}{c}{ Nivell educatiu } & \multicolumn{1}{c}{ Àrees } & Unitat didàctica \\
\hline 1r ESO & Ciències i anglès & Vertebrates \\
\hline 2n ESO & Ciències i anglès & Pressure \\
\hline 3r ESO & Ciències i anglès & The Effects of Human Activities on the Environment. \\
\hline
\end{tabular}

\section{Objectiu i preguntes de recerca}

L'objectiu del treball de recerca que centra aquest article, és determinar el grau de concordança entre les activitats d'avaluació observades a les aules AICLE d'un Institut 
de secundària, i les pràctiques d' ensenyament-aprenentatge dins d'aquest mateix context, relacionades ambdues amb les competències bàsiques Cb1: Competència comunicativa lingüística i audiovisual i Cb5: Competència d'aprendre a aprendre.

Les preguntes de recerca que se’n deriven són:

-En quina mida les activitats d'avaluació es corresponen amb les d'aprenentatge desenvolupades al llarg de cada unitat?

-Es dona als alumnes un paper actiu en les activitats d'avaluació que els permeti esdevenir coneixedors del seu procés i progrés d'aprenentatge i aprendre a autoregular? -En quina mesura les activitats d'avaluació i aprenentatge en l'ensenyament AICLE tenen en compte les competències bàsiques Cb1 i Cb5?

\section{Marc metodològic}

L'estudi es fonamenta en la recerca qualitativa-naturalistíca-etnogràfica, és a dir en una anàlisi de dades qualitatives (Seidel 1998), basat en un procés interactiu, progressiu, recursiu (sempre cal retornar a les fonts) i holístic, donat que cada part conté el total.

La recerca que es presenta s’inscriu en el paradigma de la recerca-acció, definida per Kemmis i Henry com:

[...] una forma d'investigació empresa pel participants en situacions socials amb la finalitat de millorar la racionalitat i la justícia de les seves pròpies pràctiques educatives, i també la comprensió d'aquestes pràctiques i de les situacions en les quals aquestes pràctiques es porten a terme. (1989: 2)

La recerca-acció planifica i posa en pràctica una acció pedagògica per a analitzar després els seus efectes i proposar una revisió del pla inicial, el qual serà analitzat i revisat també, i així successivament (Escobar 2000).

La investigadora d'aquest estudi té l'avantatge de ser familiar tant als participants (estudiants del Màster en pràctiques) que elaboren els objectes d'estudi o unitats didàctiques, com als receptors (estudiants d'ESO) tot comptant amb la seva col-laboració i el consentiment previ. Aquest fet afavoreix aconseguir dades naturals i permet conèixer la comunitat el millor possible per analitzar les dades des d'una perspectiva èmica (des del punt de vista del participant) i tenint en compte tota la situació (comprensió heurística del fet a observar). 
Amb l'objectiu de garantir la transversalitat en els resultats, s'estableix un protocol comú d’anàlisi per a les tres unitats didàctiques seguint els passos següents:

1- Primera aproximació crítica a les unitats didàctiques i identificació de continguts abordats en cada UD a partir dels objectius de recerca.

2- Identificació de categories i subcategories per a les activitats d'aprenentatge i d'avaluació.

3- Anàlisi de les UD per separat:

a. Anàlisi exhaustiva dels continguts de cada UD,

b. Anàlisi de les activitats d'ensenyament-aprenentatge aplicant el sistema de categories i subcategories dissenyat per l'autora en els apartats 1 i 2.

4- Posada en relació dels resultats obtinguts de l'anàlisi de cada categoria i identificació de regularitats i irregularitats.

Aquest protocol comú d’anàlisi de les dades qualitatives obtingudes es fonamenta en el mètode d'anàlisi del contingut (Cohen, Manion i Morrison 2007). Aquest mètode consisteix en reduir les dades obtingudes tot classificant-les en un nombre inferior de categories derivades de les àrees d'interès establertes prèviament (Weber 1990: 15). La categorització de les dades ens permet observar les similituds o discordances entre les unitats d'anàlisi, descriure-les davant les evidències observades, redactar les inferències que se’n deriven i assegurar la fiabilitat i viabilitat de l'anàlisi.

\section{Anàlisi}

Procedirem ara a exemplificar el protocol d'anàlisi explicitat anteriorment.

1- Primera aproximació crítica a les unitats didàctiques i identificació de continguts abordats en cada UD a partir dels objectius de recerca.

De cada unitat didàctica s'elabora una taula amb els apartats proposats per la investigadora a fi i efecte de poder visualitzar d'una forma entenedora el contingut a analitzar.

Aquests apartats són:

Taula 2: Apartats de l'anàlisi del contingut de les unitats didàctiques

\begin{tabular}{|l|c|c|c|c|c|c|}
\hline $\begin{array}{l}\text { Contingut } \\
\text { curricular }\end{array}$ & $\begin{array}{c}\text { Estratègia } \\
\text { docent } \\
\text { d'ensenya- } \\
\text { ment- } \\
\text { aprenentatge }\end{array}$ & $\begin{array}{c}\text { Tasca } \\
\text { d'ensenya- } \\
\text { ment- } \\
\text { aprenentatge }\end{array}$ & $\begin{array}{c}\text { Habilitats } \\
\text { que } \\
\text { s'esperen } \\
\text { de } \\
\text { l'alumnat }\end{array}$ & $\begin{array}{c}\text { Estratègia } \\
\text { docent } \\
\text { d'avaluació }\end{array}$ & $\begin{array}{c}\text { Tasca } \\
\text { d'avaluació }\end{array}$ & $\begin{array}{c}\text { Habilitats } \\
\text { que } \\
\text { s'esperen de } \\
\text { l'alumnat }\end{array}$ \\
\hline
\end{tabular}




\section{Identificació d'alguns dels apartats}

Estratègia docent d'ensenyament-aprenentatge: Activitat en el seu sentit més ampli que el professorat usa per a presentar el contingut a aprendre (explicació oral, presentació PowerPoint, dossier, visita, lectura comprensiva...), i per avaluar (test escrit, exposició oral, autoavaluació).

Tasca d'ensenyament- aprenentatge: Concreció de l'activitat segons la forma (individual, petit grup, gran grup...) i el contingut del material que el professorat requereix a l'alumnat per a desenvolupar la comprensió dels continguts proposats (identificar el vocabulari, emetre hipòtesis...) i per desenvolupar l'activitat d'avaluació (completar taules, elaborar i exposar mapes conceptuals...).

Habilitats que s'esperen de l'alumnat: Les habilitats que es demana a l'alumnat que apliqui per tal de portar a terme les tasques proposades, és a dir les habilitats que l'alumnat ha de posar en joc per a poder desenvolupar cada una de les tasques. El què s'espera que aporti i/o executi l'alumne (atenció, memorització, identificació, argumentar un escrit, preparar una presentació oral o amb diapositives...).

A continuació presentem un exemple d'aquest anàlisi del contingut curricular: “Animals en perill d'extinció” de la unitat didàctica dels Vertebrats (1r ESO).

Taula 3: Exemple d'anàlisi d'un dels continguts de la unitat didàctica The Vertebrates

\begin{tabular}{|l|l|l|l|l|l|l|}
\hline $\begin{array}{l}\text { Contingut } \\
\text { curricular }\end{array}$ & $\begin{array}{l}\text { Estratègia } \\
\text { docent } \\
\text { d'ensenya- } \\
\text { ment- } \\
\text { aprenentatge }\end{array}$ & $\begin{array}{l}\text { Tasca } \\
\text { d'ensenya- } \\
\text { ment- } \\
\text { aprenentatge }\end{array}$ & $\begin{array}{l}\text { Habilitats } \\
\text { que } \\
\text { s'esperen de } \\
\text { l'alumnat }\end{array}$ & $\begin{array}{l}\text { Estratègia } \\
\text { docent } \\
\text { d'avaluació }\end{array}$ & $\begin{array}{l}\text { Tasca } \\
\text { d'avaluació }\end{array}$ & $\begin{array}{l}\text { Habilitats } \\
\text { que } \\
\text { s'esperen de } \\
\text { l'alumnat }\end{array}$ \\
\hline $\begin{array}{l}\text { Animals } \\
\text { en perill } \\
\text { d'extinció. }\end{array}$ & $\begin{array}{l}\text { Lectura } \\
\text { d'experts: } \\
\text { Polar Bear. } \\
\text { Dues lectures } \\
\text { diferents sobre } \\
\text { el mateix } \\
\text { tema. de }\end{array}$ & $\begin{array}{l}\text { En parelles } \\
\text { han } \\
\text { preguntar-se i } \\
\text { contestar } \\
\text { preguntes pre- } \\
\text { establertes, } \\
\text { després de la } \\
\text { lectura } \\
\text { individual. }\end{array}$ & $\begin{array}{l}\text { Justicar i } \\
\text { explicar, } \\
\text { memoritzar, } \\
\text { fer hipòtesis, } \\
\text { establir } \\
\text { causa- } \\
\text { efecte. } \\
\text { argumentar i } \\
\text { defensar. }\end{array}$ & $\begin{array}{l}\text { Composi- } \\
\text { ció escrita. }\end{array}$ & $\begin{array}{l}\text { Individual. } \\
\text { Resum del } \\
\text { que s'ha } \\
\text { après } \\
\text { després de } \\
\text { l'activitat. }\end{array}$ & $\begin{array}{l}\text { Expressió } \\
\text { escrita. } \\
\text { Argumentar. } \\
\text { Identificar. } \\
\text { Explicar. }\end{array}$ \\
\end{tabular}

2- Identificació de categories i subcategories per a les activitats d'aprenentatge i avaluació

Una vegada realitzada l'aproximació crítica i identificació del contingut de les tres unitats didàctiques, s'estableixen nou categories per a l'anàlisi de les estratègies docents (activitats) d’avaluació i aprenentatge, les quals són: 
1:Activitats comunicatives receptives. 2:Activitats comunicatives productives i interactives. 3:Habilitats cognitives-lingüístiques. 4:Habilitats cognitives. 5:Format de la informació en les activitats de recepció i producció. 6:Suport per fer la tasca.

7:Control/direcció de la tasca. 8:Balanç entre avaluació formativa i certificativa. 9:Reflexió.

Aquestes nou categories s'han establert prenent com a referència a Jorba, Gómez i Prat (2000: 24-35). Ens serviran per a analitzar l'existència i el tipus de comunicació i interacció (categories 1, 2, 3, 4 i 5), de contingut (categories 5, 6 i 7) i d'avaluació (categories 8 i 9) en les activitats d'ensenyament-aprenentatge i les d'avaluació.

Cada una de les categories es relaciona amb les activitats i les tasques corresponents, tal i com s’indica amb alguns exemples a la taula següent:

Taula 4: Exemples de categorització de les activitats d'ensenyament-aprenentatge i avaluació

\begin{tabular}{|c|c|c|}
\hline $\begin{array}{l}\text { Categories de les } \\
\text { estratègies doce nts. }\end{array}$ & $\begin{array}{l}\text { Exe mples d'estratègies } \\
\text { docents d'e/a } \mathbf{i} \text { avaluació }\end{array}$ & Exemples de tasques d'e/a $i$ avaluació \\
\hline $\begin{array}{c}\text { 1- Activitats } \\
\text { comunicatives receptives }\end{array}$ & $\begin{array}{c}\text { *Lectura comprensiva } \\
* \text { Escoltar/visualitzar un vídeo }\end{array}$ & $\begin{array}{c}\text { *Omplir els buits d'un text donat } \\
* \text { Buscar vocabulari en una sopa de lletres }\end{array}$ \\
\hline $\begin{array}{c}\text { 2-Activitats } \\
\text { comunicatives } \\
\text { productives i interactives }\end{array}$ & $\begin{array}{l}\text { *Debat a 1'aula } \\
\text { *Presentació oral d'un mural }\end{array}$ & $\begin{array}{l}\text { *Fer preguntes i respostes orals } \\
\text { *Comentar les conclusions } \\
\text { *Redacció de frases en format esquema }\end{array}$ \\
\hline $\begin{array}{l}\text { 3- Habilitats cognitives } \\
\text { lingüistiques }\end{array}$ & $*$ Elaborar un gràfic & *Escriure uns comparació dels resultats \\
\hline 4 Habilitats cognitives & *Experiment de laboratori & *Emetre hipòtesis \\
\hline $\begin{array}{c}\text { 5- Format de la } \\
\text { informació en les } \\
\text { activitats de recepció i } \\
\text { producció }\end{array}$ & $\begin{array}{l}\text { *Presentació visual d'una } \\
\text { cadena alimentària }\end{array}$ & $\begin{array}{c}\text { *Relacionar cada element i elaborar un } \\
\text { text explicatiu }\end{array}$ \\
\hline $\begin{array}{l}\text { 6- Suport per elaborar } \\
\text { 1'activitat }\end{array}$ & *Üs del diccionari & *Elaborar un petit glossari \\
\hline $\begin{array}{c}\text { 7- Controlidirecció de } \\
\text { 1'activitat }\end{array}$ & $\begin{array}{l}\text { *Lectura d'experts en parelles } \\
\text { (escrits diferents i } \\
\text { comple mentaris) }\end{array}$ & $\begin{array}{c}\text { *Formular i contestar preguntes entre la } \\
\text { parella }\end{array}$ \\
\hline $\begin{array}{l}\text { 8- Balanç entre avaluació } \\
\text { formativa i certificativa }\end{array}$ & *Exercici test & *Distingir la resposta correcta \\
\hline 9- Reflexió de 1'alumnat. & *Treball en grup & *Pauta d'autoavaluació del grup \\
\hline
\end{tabular}

A partir d'aquesta primera categorització s'estableixen unes subcategories que intenten concretar, per a cada categoria, les habilitats que s'esperen de l'alumnat, en referència a la informació que es vol obtenir pel que fa a l'assoliment de les dues competències 
bàsiques Cb1 i Cb5. A continuació presentem dos exemples de categories amb les subcategeories corresponents:

Taula 5: Exemples de subcategories

\begin{tabular}{|l|l|}
\hline $\begin{array}{l}\text { Exemples de categories de } \\
\text { l'estratègia docent (activitat). }\end{array}$ & Sub-categories de cada categoria \\
\hline \multirow{4}{*}{ 4- Habilitats cognitives } & $\begin{array}{l}\text { Comparar: confrontar una cosa amb una altra per a establir } \\
\text { similituds i diferències }\end{array}$ \\
\cline { 2 - 2 } & Classificar: distribuir en grups segons un sistema \\
\cline { 2 - 2 } & Inferir/deduir: treure conseqüències \\
\cline { 2 - 2 } & Planificar/dissenyar: estructurar el contingut segons un ordre \\
\hline \multirow{2}{*}{$\begin{array}{l}\text { 5- Format de la informació en } \\
\text { les activitats de producció i } \\
\text { recepció }\end{array}$} & Presentació visual: per mitjà de la visió (imatges, gràfics...) \\
\cline { 2 - 2 } & Presentació oral: per mitjà de la parla \\
\cline { 2 - 2 } & Presentació digital: per mitjà de l'ordinador \\
\cline { 2 - 2 } & Presentació escrita: per mitjà del text escrit \\
\hline
\end{tabular}

\section{3-Anàlisi de les UD per separat}

\section{3.a- Anàlisi exhaustiva dels continguts de cada UD}

Amb l'objectiu de poder presentar un producte el màxim de comprensible i transferible possible que ens aporti una anàlisi fiable, s’agrupen les tasques de característiques similars per a cada estratègia docent (activitat), tal i com s'exemplifica a la taula següent:

Taula 6: Exemples de tasques per a cada estratègia que el docent presenta i/o demana

\begin{tabular}{|l|l|}
\hline $\begin{array}{l}\text { Estratègia docent } \\
\text { (activitat) }\end{array}$ & Tasques \\
\hline Prova escrita & Desenvolupament i/o resposta de preguntes donades en situació d'examen \\
\hline Presentació Visual & Elaboració i presentació a l'aula d'un producte (pòster, mural, gràfic) \\
\hline Presentació Audiovisual & $\begin{array}{l}\text { Audició i visualització d'un vídeo i omplir espais buits d'un text donat. } \\
\text { Elaboració i presentació d'un muntatge audiovisual en grup d'algun apartat } \\
\text { de la unitat. }\end{array}$ \\
\hline Presentació digital (oral) & $\begin{array}{l}\text { Elaboració i presentació d'un muntatge d'imatges i textos amb suport } \\
\text { digital. }\end{array}$ \\
\hline Lectura d'experts & $\begin{array}{l}\text { Lectura i comprensió individual de dos textos complementaris amb } \\
\text { intercanvi d'informació entre els alumnes. }\end{array}$ \\
\hline
\end{tabular}

\section{3.b- Anàlisi de les activitats d'ensenyament-aprenentatge aplicant el sistema de} categories i subcategories dissenyats en els apartats 1 i 2

Amb totes les dades dels anteriors apartats s'elabora una anàlisi interpretativa en forma de graella, on s’identifica amb creus les estratègies o activitats i tasques emprades a 
l'aula, tant les d'ensenyament-aprenentatge com les d'avaluació per a cada una de les tres unitats didàctiques i per a cada categoria establerta.

Presentem a continuació l'anàlisi de la categoria activitats comunicatives receptives, de cada una de les tres UD.

Taula 7: Anàlisi interpretativa de la categoria 1 de la unitat didàctica The Vertebrates

\begin{tabular}{|c|c|c|c|c|c|c|c|c|c|c|c|c|c|c|c|}
\hline \multicolumn{2}{|l|}{ Vertebrates } & \multicolumn{7}{|c|}{$\begin{array}{l}\text { Es tratègies doce nts } \\
\text { d'avaluació }\end{array}$} & \multicolumn{7}{|c|}{$\begin{array}{c}\text { Es tratègies docents } \\
\text { d'ensenyament- aprenentatge }\end{array}$} \\
\hline Categories & Subcategories & 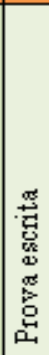 & 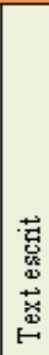 & 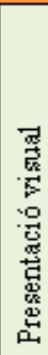 & 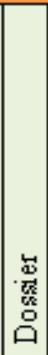 & 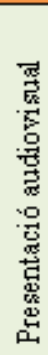 & 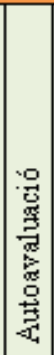 & 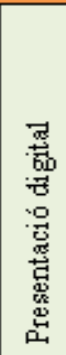 & 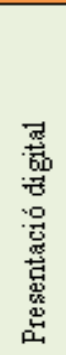 & 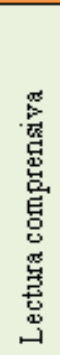 & 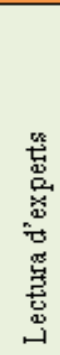 & 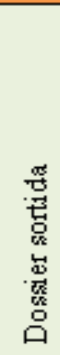 & 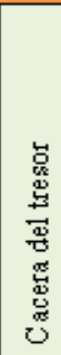 & 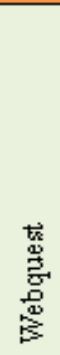 & 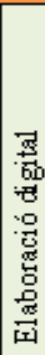 \\
\hline & & \multicolumn{14}{|c|}{$\begin{array}{l}\text { Anàlisi de les tasques d'avaluació i d'ens enyament- aprenentatge de } \\
\text { cada estratègia segons la taula } 6 \text { d'activitats i tasques: }\end{array}$} \\
\hline \multirow{3}{*}{$\begin{array}{l}\text { 1.Activitats } \\
\text { comunicatives } \\
\text { receptives }\end{array}$} & $\begin{array}{l}\text { Estudiant- } \\
\text { material escolar }\end{array}$ & $\mathrm{x}$ & \begin{tabular}{|l|}
$\mathrm{x}$ \\
\end{tabular} & $\mathrm{x}$ & $\mathrm{x}$ & $\mathrm{x}$ & $\mathrm{x}$ & $x$ & & $\mathrm{x}$ & $\mathrm{x}$ & $x$ & $\mathrm{x}$ & $\mathrm{x}$ & $\mathrm{x}$ \\
\hline & $\begin{array}{l}\text { Estudiant- } \\
\text { estudiant }\end{array}$ & & & $\mathrm{x}$ & & $\mathrm{x}$ & & $\mathrm{x}$ & & & $\mathrm{x}$ & $\mathrm{x}$ & $\mathrm{x}$ & $\mathrm{x}$ & $\mathrm{x}$ \\
\hline & $\begin{array}{l}\text { Professor/a- } \\
\text { classe }\end{array}$ & & & & & & & & $\mathrm{x}$ & & & & & & \\
\hline
\end{tabular}

Taula 8: Anàlisi interpretativa de la categoria 1 de la unitat didàctica The Pressure

\begin{tabular}{|c|c|c|c|c|c|c|c|c|c|c|c|c|c|c|}
\hline \multicolumn{2}{|c|}{ Pressure } & \multicolumn{5}{|c|}{$\begin{array}{l}\text { Es tratègies doce nts } \\
\text { d'avaluació }\end{array}$} & \multicolumn{8}{|c|}{$\begin{array}{c}\text { Es tratègies docents } \\
\text { d'ensenyament- aprenentatge }\end{array}$} \\
\hline Categories & Subcategories & 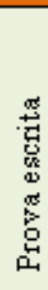 & 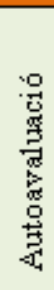 & 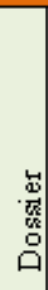 & 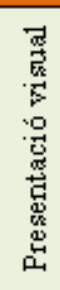 & 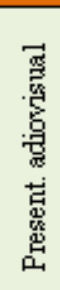 & 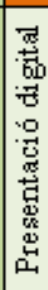 & 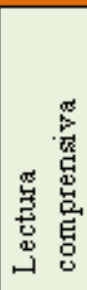 & 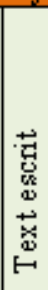 & 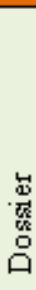 & 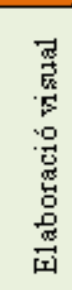 & 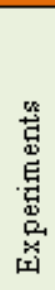 & 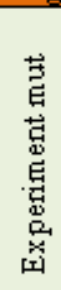 & 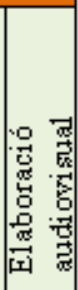 \\
\hline & & \multicolumn{13}{|c|}{$\begin{array}{l}\text { Anàlisi de les tasques d'avaluació i d'ensenyament- aprenentatge } \\
\text { de cada estratègia segons la taula } 6 \text { d'activitats i tasques: }\end{array}$} \\
\hline \multirow{3}{*}{$\begin{array}{l}\text { 1.Activitats } \\
\text { comunicatives } \\
\text { receptives }\end{array}$} & $\begin{array}{l}\text { Estudiant- } \\
\text { material escolar }\end{array}$ & $\mathrm{x}$ & $\mathrm{x}$ & $\mathrm{x}$ & $\mathrm{x}$ & & & $x$ & $\mathrm{x}$ & $\mathrm{x}$ & $\mathrm{x}$ & $\mathrm{x}$ & $\mathrm{x}$ & \\
\hline & $\begin{array}{l}\text { Estudiant- } \\
\text { estudiant }\end{array}$ & & & & $\mathrm{x}$ & $\mathrm{x}$ & & $\mathrm{x}$ & $\mathrm{x}$ & $\mathrm{x}$ & $\mathrm{x}$ & & & $\mathrm{x}$ \\
\hline & $\begin{array}{l}\text { Professor/a- } \\
\text { classe }\end{array}$ & & & & & & $\mathrm{x}$ & $\mathrm{x}$ & $\mathrm{x}$ & $\mathrm{x}$ & & $\mathrm{x}$ & & \\
\hline
\end{tabular}


Taula 9: Anàlisi interpretativa de la categoria 1 de la unitat didàctica The effects of human activity on the Environment

\begin{tabular}{|c|c|c|c|c|c|c|c|c|c|c|c|c|c|c|c|}
\hline \multicolumn{2}{|c|}{$\begin{array}{l}\text { The effects of human activity on } \\
\text { the Enviro nment }\end{array}$} & \multicolumn{5}{|c|}{$\begin{array}{l}\text { Es tratègies doce nts } \\
\text { d'avaluació }\end{array}$} & \multicolumn{9}{|c|}{$\begin{array}{c}\text { Es tratègies doce nts d'e nsenyament- } \\
\text { aprenentatge }\end{array}$} \\
\hline Categories & Sub-categories & 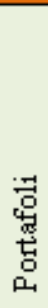 & 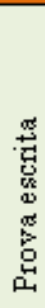 & 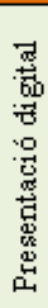 & 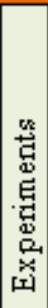 & 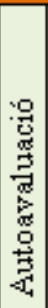 & 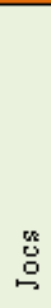 & 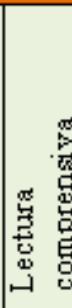 & 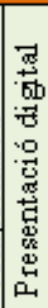 & 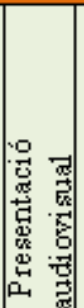 & 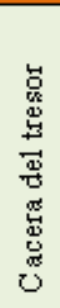 & 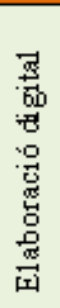 & 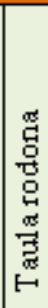 & 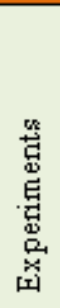 & 总 \\
\hline & & \multicolumn{14}{|c|}{$\begin{array}{l}\text { Anàlisi de les tasques d'avaluació i d'ensenyament- aprenentatge de } \\
\text { cada estratègia segons la taula } 6 \text { d'activitats i tasques: }\end{array}$} \\
\hline \multirow{3}{*}{$\begin{array}{l}\text { 1.Activitats } \\
\text { comunicatives } \\
\text { receptives }\end{array}$} & $\begin{array}{l}\text { Estudiant- } \\
\text { material escolar }\end{array}$ & $\mathrm{x}$ & $\mathrm{x}$ & $\mathrm{x}$ & & $\mathrm{x}$ & $\mathrm{x}$ & $\mathrm{x}$ & $\mathrm{x}$ & $\mathrm{x}$ & $\mathrm{x}$ & $\mathrm{x}$ & $\mathrm{x}$ & $\mathrm{x}$ & \\
\hline & $\begin{array}{l}\text { Estudiant- } \\
\text { estudiant }\end{array}$ & & & $\mathrm{x}$ & $\mathrm{x}$ & & $\mathrm{x}$ & & & & $\mathrm{x}$ & $\mathrm{x}$ & $\mathrm{x}$ & $\mathrm{x}$ & $\mathrm{x}$ \\
\hline & $\begin{array}{l}\text { Professor/a- } \\
\text { classe }\end{array}$ & & & & $x$ & & $\mathrm{x}$ & & $x$ & $\mathrm{x}$ & & & & & $\mathrm{x}$ \\
\hline
\end{tabular}

4- Posada en relació dels resultats obtinguts de l'anàlisi de cada categoria i identificació de regularitats i irregularitats

Tal i com s'ha dit a l'apartat de metodologia, l'anàlisi de cada una de les categories ens permet identificar les similituds i/o discordances entre les unitats d'anàlisi i descriureles davant les evidències observades.

Presentem ara algunes de les observacions que corresponen a la categoria 1: activitats comunicatives receptives, les quals ens ajudaran a elaborar les conclusions de l'estudi:

1. Observem que els estudiants interaccionen majoritàriament amb material escolar presentat pel professorat en format paper, digital i/o audiovisual.

2. Detectem l'ús de noves tecnologies (TIC) en les tasques d'ensenyamentaprenentatge i concretament en les de presentació digital a l’avaluació.

3. El grau d’interacció es mostra més elevat entre els estudiants en les tasques d'ensenyament-aprenentatge, degut a l'elaboració de treballs en grup i en menys quantia a les tasques d'avaluació, tot i que s’observa l'exposició oral per part dels alumnes dels productes finals d’avaluació. 


\section{Conclusions}

A partir de l'anàlisi de les activitats i tasques AICLE categoritzades en les tres unitats didàctiques de referència, observem que d'una forma global es potencia el paper de l'alumnat en el seu procés d'aprenentatge, tot planificant diverses tipologies de tasques tant d'ensenyament-aprenentatge com d'avaluació per a atendre els diferents estils i necessitats d'aprenentatge de l'alumnat. Amb les activitats d'autoavaluació o per parelles es transfereix part de la responsabilitat de prendre decisions del professorat cap a l'aprenent (Boud 2003: 9), deixant de ser aquest un mer espectador per a convertir-se en participant i coneixedor del propi procés d'aprenentatge, i adquirint consciència de les seves pròpies capacitats (Sanmartí 2007).

S’observa també l'existència d'una concordança entre les activitats i tasques que condueixen a l'alumnat a treballar la seva competència comunicativa i la d'aprendre a aprendre, com per exemple el treball en grup on interactuen amb els/les companys/es. La interacció segons Vygotsky (1978) sembla que faciliti el procés d'interiorització que condueix a l'alumnat a passar del que pot realitzar amb l'ajut dels altres al que és capaç de realitzar per si mateix, de manera autònoma.

Observem que en la categoria d'activitats comunicatives receptives, hi ha una manca d'activitats d'avaluació de comprensió oral. També s’observa una descompensació de tasques d'avaluació de les habilitats cognitives-lingüístiques i les cognitives com definir i comparar.

Acabem aquest apartat de conclusions amb la proposta de tres aspectes observats com a millorables en entorns AICLE. Un d'ells és l'ús del Portafoli com a eina autoreguladora de selecció i reflexió per part de l'alumnat (Arter i Spandel 1992; Escobar 2003; Sanmartí 2007). En segon lloc l'existència de feedback entre professorat i alumnat després de la realització de les activitats, entès com a instrument d'autoregulació monitoritzat pel docent com a mediador, orientant a l'alumnat i donantli evidències del seu propi progrés (Sanmartí 2007). Per últim però no menys important, l'existència d'activitats d'autoavaluació del treball interactiu (en grup) que condueix a l'alumnat a la construcció de coneixement significatiu.

L'anàlisi objecte d'aquest estudi ens permet concloure que els entorns AICLE són espais innovadors que aporten instruments i estratègies de canvi en el funcionament 
dels centres educatius per a adaptar-se a una societat plurilingüe i, on es posa a l'abast dels estudiants una diversificació d'eines d'aprenentatge i d'avaluació que els ajuden a desenvolupar les habilitats i estratègies necessàries per a esdevenir competents. L'estudiant esdevé el centre de l'aprenentatge i de l'avaluació, amb un paper participatiu que el fa coneixedor del propi procés i progrés d’aprenentatge. La recercaacció ens ha confirmat a través de l'avaluació predictiva de seqüències didàctiques, l'acceptabilitat global de la proposta permetent alhora la identificació d’àrees de millora.

\section{Referències bibliogràfiques}

Allal, L. (2006). La fonction de régulation de l'évaluation: constructions théroiques et limites empiriques, A: Figari, G. i Mottier Lopez, L. (ed): Recherche sur l'évaluation en éducation (pp. 223-230). Paris: L’Harmattan.

Arter, J. \& Spandel, V. (1992). NCME instructional module: Using portfolios of student work in instruction and assessment. Educational Measurement: Issues and Practice, 11(1): 36-44.

Bazerman, C. (2002). What is not institutionally visible does not Count: The problem of making activity assessable, aaccountable and plannable. In C. Bazeman, \& D. Russel (Eds.), Writing selves and societies (pp. 428-482). Fort Collins, Colorado: The WAC Clearinghouse and Mind, Culture, and Activity.

Boud, D. (2003). Sustainable assessment: Rethinking assessment for the learning society. Studies in Continuing Education, 22: 151-67.

Cohen, L., Manion, L. \& Morrison, K. (2007). Research methods in education (sixth edition). London \& New York: Routledge: Taylor \& Francis Group.

Corredera, A. (2008). Uso de la lengua extranjera en tareas para aprender ciencias en inglés: ¿hablan en inglés? A: Monroy, R. i Sánchez, A. (Coords.) 25 Años de lingüística aplicada en España: Hitos y retos / 25 Years of Applied Linguistics in Spain: Milestones and Challenges (pp. 295-307). Murcia: Editum.

Dalton-Puffer, C. (2007). Discourse in Content and Language Integrated Learning (CLIL) classrooms. Amsterdam: John Benjamins.

De Ketele, J.M. (2006). La recherche en évaluation: propos synthétiques et prospectifs. Mesure et évaluation en education, 29(1): 99-118.

DOGC núm. 4915. Decret 143/2007 de 26 de juny. Pàg. 21870.Article 7. Punt 1

Escobar, C. (2000). El portafolio oral como instrumento de evaluación formativa en el aula de lengua extranjera. Tesis doctoral no publicada. Departament de Didàctica de la llengua i la literatura,Universitat Autònoma de Barcelona.

Escobar, C. (2002). Promoting and assessing oral interaction in the classroom: The oral portfolio. In C. Escobar \& A. Hasselgreen (Eds.) Assessing secondary students' interaction: Opening paths for a better learning (pp. 7-27). Barcelona: APAC Monographs.

Escobar, C. (2003). La evaluación de la interacción oral. Mosaico, 10: 18-25. 
Escobar, C. (2004). Content and language integrated learning: Do they learn content? Do they learn language? In J.D. Anderson, J.M. Oro, \& J. Varela (Eds). Linguistic perspectives from the classroom: Language teaching in a multicultural Europe (pp. 27-38). Santiago de Compostela: Universidade de Santiago de Compostela.

Escobar, C. (2007). Mesurament de competències lingüístiques en aules AICLE, en contextos multilingües: allò que els números amaguen. A: Guasch, O. i Nussbaum, L. (Coords.) Aproximacions a la noció de competència multilingüe, pp. 133-146. Bellaterra: Servei de Publicacions de la UAB.

Escobar, C. (2011). Colaboración interdisciplinar, partenariado y centros de formación docente: Tres ejes para sustentar la formación del profesorado AICLE. A: Escobar Urmeneta, C. i Nussbaum, L. (Coords.) Aprendre en una altra llengua / Learning through another language / Aprender en otra lengua (pp. 201-227). Bellaterra: Servei de publicacions de la UAB.

Evnitskaya, N. y Aceros, J.C. (2008). "We are a good team”: El contrato didáctico en parejas de aprendices de lengua extranjera. Revista Española de Lingüística Aplicada, 21: 45-70.

Horrillo, Z. (2010). A case study of cross-curricular dialogue as a part of teacher education in the CLIL (Content and Language Integrated Learning) approach. Critical and Reflective Practice in Education (CRPE), 2: 4-17.

Jiménez, M. (2010). Aprenentatge Integrat de Continguts i Llengües (AICLE) i alumnes amb necessitats educatives especials: un estudi de cas. Treball de recerca no publicat. Màster oficial en Didàctica de la llengua i la literatura de la UAB. Disponible a: http://grupsderecerca.uab.cat/clilsi/content/publicacions-en1\%C3\%ADnia-de-lequip-clil-si. Darrera consulta el 3 de maig de 2011.

Jorba, J.; Gómez, I. y Prat, A. (2000). Hablar y escribir para aprender: uso de la lengua en situación de enseñanza-aprendizaje desde las áreas curriculares. Madrid: Editorial Síntesis.

Kemmis, S. \& Henry, J. (1989). Action research. IATEFL Newsletter, 102: 2-3.

Navés, M. T. y Muñoz, C. (1999). Experiencias de AICLE en España. A: Marsh, D. i Langé, G. (Coords.) Implementing Content and Language Integrated Learning. A Research-driven TIE-CLIL Foundation Course. Reader (pp. 131-144). University of Jyväskylä: Continuing Education Center.

Nussbaum, L. y Tusón, A. (2006). El aula como espacio cultural y discursivo (reedició). A: Lomas (comp.) La educación lingüística y el aprendizaje de las competencias comunicativas, pp. 153-164. Bogotà: Cooperativa Editorial Magisterio.

OCDE. (2005). Le programme DeSeCo. La définition et la sélection des compétences clés: Résumé. http://www.oecd.org/dataoecd/47/61/35070367.pdf

Pallarès, O. (2010). 'Think and Discuss': Disseny de tasques per a la construcció de competències discursives a l'aula AICLE de matemàtiques. Un estudi de cas. Treball de recerca no publicat. Màster oficial en Didàctica de la llengua i la literatura de la UAB. Disponible a: http://grupsderecerca.uab.cat/clilsi/content/publicacions-en-l\%C3\%ADnia-delequip-clil-si. Darrera consulta el 3 de maig de 2011.

Ribas, T. (1998). L'avaluació formativa en l'àrea de llengua. Graó. Barcelona.

Ribas, T. (2009). L'avaluació i l'ensenyament de llengües: dos àmbits que s’aproximen. Articles de Didàctica de la Llengua i la literatura, 47: 10-25.

Sanmartí, N. (2007). 10 ideas clave. Evaluar para aprender. Graó: Barcelona. 
Seidel, J.V. (1998). QDA. Qualitative Data Analysis. Qualis Research. Disponible a www.qualisresearch.com.

Tapias, N. (2010). El camí de la tasca a l'activitat: el treball en petit grup en enfocaments AILCE des de la perspectiva de la Teoria de l'Activitat. Treball de recerca no publicat. Màster oficial en Didàctica de la llengua i la literatura de la UAB. Disponible a: http://grupsderecerca.uab.cat/clilsi/content/publicacions-en1\%C3\%ADnia-de-lequip-clil-si. Darrera consulta el 3 de maig de 2011.

Vygotsky, L. (1978). Mind in Society. Cambridge, MA: Harvard University Press.

Weber, R. P. (1990). Basic Content Analysis (2nd edition). Thousand Oaks, CA: Sage.

Wolf, K. (1991). The schoolteacher's portfolio: Issues in design, implementation and education. Tha Phi Delta Kappen, 73(2): 129-136.

\section{Notes}

1 Estudi realitzat dins del Marc del Projecte "Discurs Acadèmic en Llengua Estrangera: Aprenentatge i

Avaluació de Continguts Científics en l'Aula Multilingüe (DALE-APECS)”, referència EDU2010-15783, finançat pel MICINN (http://hdl.handle.net/2072/97380).

2 http://grupsderecerca.uab.cat/clilsi/

3 http://www.greip.uab.cat/

\section{Referència de l'autora:}

Elisabeth Eixarch Domènech és professora catedràtica de llengua anglesa i té el titol del Màster d'Investigació en Didàctica de la Llengua i la Literatura (DLL) de la Universitat Autònoma de Barcelona (2010). El 2010 va obtenir una llicència d'estudis del Departament d'Ensenyament. Ha estat directora de l'Institut Sabadell durant vuit anys i està proposada com a directora de l'Institut Les Aymerigues de Terrassa, un centre de nova creació 2011. És col-laboradora de la Universitat Autònoma de Barcelona com a tutora de pràctiques d'alumnat del Màster en Formació del Professorat de Secundària Obligatòria i Batxillerat. En el marc del grup de recerca en Ensenyament i Interacció Plurilingües (GREIP) participa en grup de treball Content and Language Integrated Learning-Semiimmersió (CLIL-SI). Participa en el Programa de Formació del Professorat Formador de l'ICE de la UAB com a component de Formació de formadors GREIP: La semi-immersió. CLIL-SI. Actualment forma part com a professora-investigadora en el Projecte "Discurs Acadèmic en Llengua Estrangera: Aprenentatge i Avaluació de Continguts Científics en l'Aula Multilingüe" (DALE-APECS) de la UAB.

Email: eeixarch@xtec.cat 